\title{
Towards a new method for coating heritage lead
}

\author{
Rosie A Grayburn ${ }^{1,2^{*}}$, Mark Dowsett ${ }^{1}$, Michel De Keersmaecker ${ }^{2}$, Dipanjan Banerjee ${ }^{3}$, Simon Brown $n^{4,5}$ \\ and Annemie Adriaens ${ }^{2}$
}

\begin{abstract}
Background: Ethanolic solutions of long-chain carboxylic acids can be applied to lead metal substrates to form a coating of lead carboxylate which provides protection against atmospheric pollutants.

Results and conclusions: In this paper we describe the optimal inhibitor concentration for the coating on lead. Electrochemical impedance data taken before and after immersion in media modelling oak emitted volatile organic compounds (VOCs) polluted atmospheres show that coating effectiveness decreases after exposure, but the effect is lessened if longer chain carboxylates are used.
\end{abstract}

Keywords: Heritage lead, Organic coatings, EIS, XRD, Corrosion

\section{Introduction}

Heritage metals are often coated as part of a conservation treatment to protect the metal surface from atmospheric deteriogens. At the same time, the coating is expected to both preserve the aesthetic appeal of the artefact and be retreatable. Common protective coatings used in conservation practice are paraffin and microcrystalline waxes [1]. These coatings are applied physically to a surface. Inhibitive coatings on the other hand form a protective layer on a surface after a chemical reaction.

Lead is of particular interest to conservation scientists due to its surface reactivity in air and its occurrence in reactive atmospheric environments such as within pipe organs [2], the proximity of VOC-emitting oak to lead pipes creating the ideal conditions for corrosion. Another similar example is the storage of small lead artefacts in wooden display cases.

Long-chain carboxylic acids have been studied as possible corrosion inhibiting coatings for lead [3-8] and other heritage metals [9-11]. These coatings are usually formed by the immersion of the lead sample into an aqueous solution of the sodium salt of the carboxylate [3]. For lead samples, a lead dicarboxylate coating forms on the surface, the carboxylic acid having reacted with the uppermost layer of lead atoms. Typically, studies have focussed on

\footnotetext{
* Correspondence: rosie.grayburn@ugent.be

${ }^{1}$ Department of Physics, University of Warwick, Coventry CV4 7AL, UK

${ }^{2}$ Department of Analytical Chemistry, Ghent University, Ghent 9000, Belgium

Full list of author information is available at the end of the article
}

chain lengths up to the decanoate because the sodium salts are reasonably water soluble to that point.

Long-chain carboxylic acids are cheap and readily available. The coating precursor solution is also easy to produce. As opposed to conservation waxes, which are derived from crude oil, these coatings are derived from natural fatty acids, thus making these coatings the most 'environmentally-friendly' option. However, the solubility of the sodium carboxylates above the decanoate becomes too low for use in aqueous deposition. In addition, decanoic acid has a distinctive odour, which deters application.

In this work we exploit the solubility of some long chain carboxylates in ethanol and use this property to move towards a new method of coating lead metal samples. The longer chains are expected to improve coating effectiveness due to increased stability with chain length [12]. Impedance measurements are used to determine coating effectiveness, whereas time-lapse synchrotron and laboratory X-ray diffraction (XRD) are used to look at drying properties and coating thickness respectively.

\section{Results and discussion \\ Sample preparation}

Tetradecanoic acid (or myristic acid) $\mathrm{CH}_{3}\left(\mathrm{CH}_{2}\right)_{12} \mathrm{COOH}$ herein abbreviated to $\mathrm{C}_{14}$ was originally chosen as a candidate for coating development due to its high solubility in ethanol compared to longer chain carboxylates. A concentration of $0.05 \mathrm{~mol} \mathrm{~L}^{-1}$ was initially used for 
direct comparison to previous work using sodium carboxylates in aqueous solution $[4,5,7,8]$.

Several methods of application to the lead surface were attempted. The solution can be applied to the surface by immersion or spraying, which makes it easy to use for large surface areas. Brush coating is impractical due to the low viscosity of the solution. Upon drying, the coating forms immediately to give a matt appearance and the surface often appears darker than when freshly polished (Figure 1).

\section{Synchrotron x-ray diffraction of coating formation}

Figure 2 shows the synchrotron X-ray diffraction (SR$\mathrm{XRD})$ results from two coating experiments using a $\mathrm{C}_{14}$ ethanolic solution on bare lead to investigate the coating mechanism. In Figure 2A the upper panel shows a composite image formed from a time-lapse sequence of 293 XRD patterns measured on a lead surface immersed in solution for 10 hours. The patterns were extracted from 2-D diffractograms and the images shown here were generated by using one pattern per horizontal row of the image to modulate the image intensity. Peaks in a sequence of patterns thus show up as bright vertical lines on the image. Although the broad lines to the left of the $\mathrm{Pb} 111$ reflection may be evidence of a nano-crystalline lead carboxylate or a gel on the surface, there is no evidence of well-defined crystal growth or increasing layer thickness with time. This contrasts sharply with the effects of immersion in aqueous sodium decanoate where crystalline layer growth takes place in solution [4], The lower panel shows a similar sequence of 28 patterns formed on drying the above surface in air: Reflections due to $\mathrm{Pb}\left(\mathrm{C}_{14}\right)_{2}$ appear after a few minutes. In Figure $2 \mathrm{~B}$ we show 10 consecutive patterns for the drying sequence from an experiment where drops of the coating solution were flowed across the lead surface during surface analysis, allowing immediate evaporation. The figure shows the $\mathrm{Pb}\left(\mathrm{C}_{14}\right)_{2}$ layer forming immediately on contact with the inhibitor solution (reflections labelled 0010 to 0026 from preliminary indexing of this pattern). However, the results show that peak areas have not yet reached a steady state at the final scan. This is due to incomplete drying - i.e. there is still ethanol present in the layer. The only evidence of an 'intermediate' stage prior to final layer formation are the broad lead carboxylate peaks at $22^{\circ}$ and above which develop during the 'wetting' stage. These peaks become more defined when drying commences and could correspond to a nanocrystalline or gel layer of lead tetradecanoate as described above. The layer forms when the carboxylic acid has reacted with the surface lead oxide but some ethanol molecules still associate with the long-chain carboxylic acid. The broadening occurs only at peaks of higher $2 \Theta$, which suggests that ethanol associates with a specific part of the carboxylic acid chain. Other reflections in these patterns may be higher order reflections from the lead carboxylate structure or unreacted carboxylic acid.

From the above we see that the lead tetradecanoate coating forms immediately on the application and evaporation of the solution thus providing a rapid treatment (no soaking is required). An oxide layer forms on the lead immediately after polishing due to its high reactivity in air. Carboxylate peaks obscure any possible litharge detection in Figure 2 and SR-XRD is unable to detect monolayers of lead oxide so we cannot deduce its involvement in the mechanism of formation, but we may infer it. The extent of dissociation of the acid in ethanol is unknown but the result would be the same if the acid were partially or fully dissociated into ions:

$$
\begin{aligned}
\mathrm{PbO}(\text { ads }) & +2 \mathrm{CH}_{3}\left(\mathrm{CH}_{2}\right)_{12} \mathrm{COO}^{-} \\
& +2 \mathrm{H}^{+} \rightarrow \mathrm{Pb}\left(\mathrm{CH}_{3}\left(\mathrm{CH}_{2}\right)_{12} \mathrm{COO}\right)_{2}+\mathrm{H}_{2} \mathrm{O}
\end{aligned}
$$

Figure 3A shows an optical microscopy image taken of a coupon coated by immersion for 24 hours in an ethanolic solution of tetradecanoic acid. The surface appears smooth but cracks show that the coating is soft and easily scratched. Figure $3 \mathrm{~B}$ shows a scanning electron micrograph of the coated lead surface. The coating is not smooth at this scale and is formed of a layer of $1 \mu \mathrm{m}$ length microcrystals. These differ in morphology from the lamellar crystal growth observed from lead carboxylate growth from aqueous solutions of sodium carboxylate [4]. The thickness of this layer can be calculated semi-quantitatively using XRD.

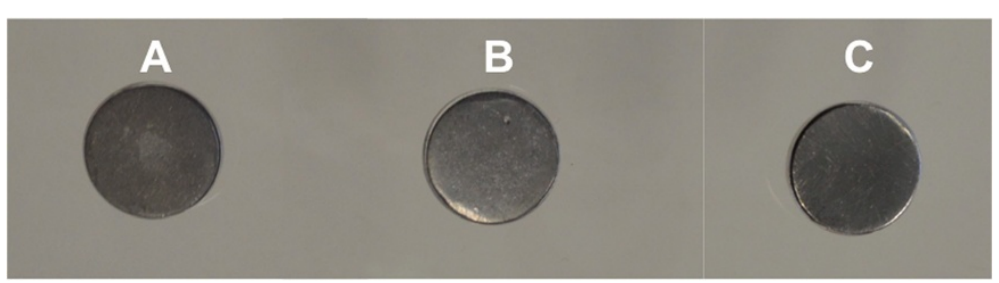

Figure 1 Photograph of C14 coated (A), C18 coated (B) and bare lead samples (C). 


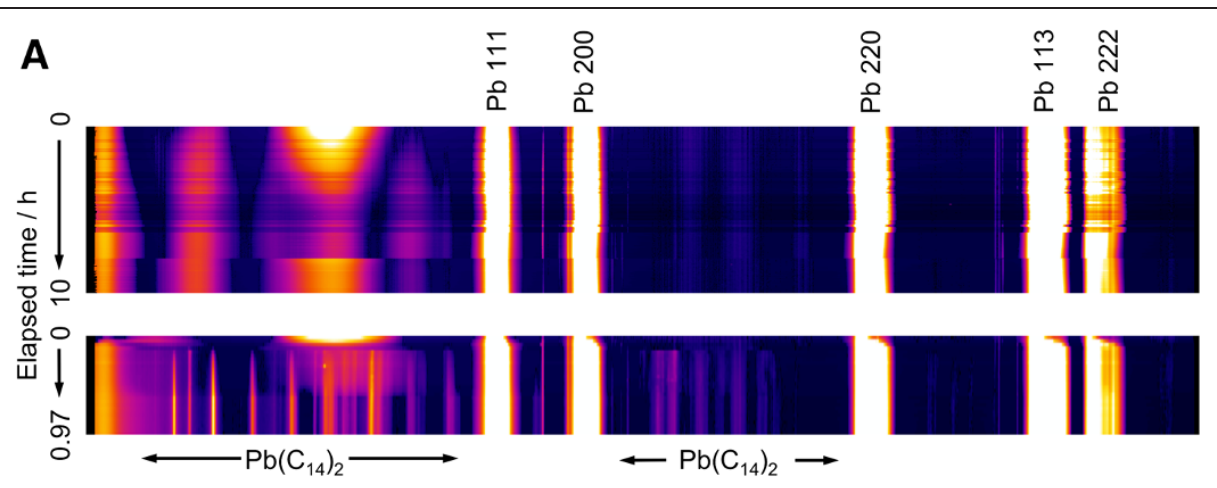

B

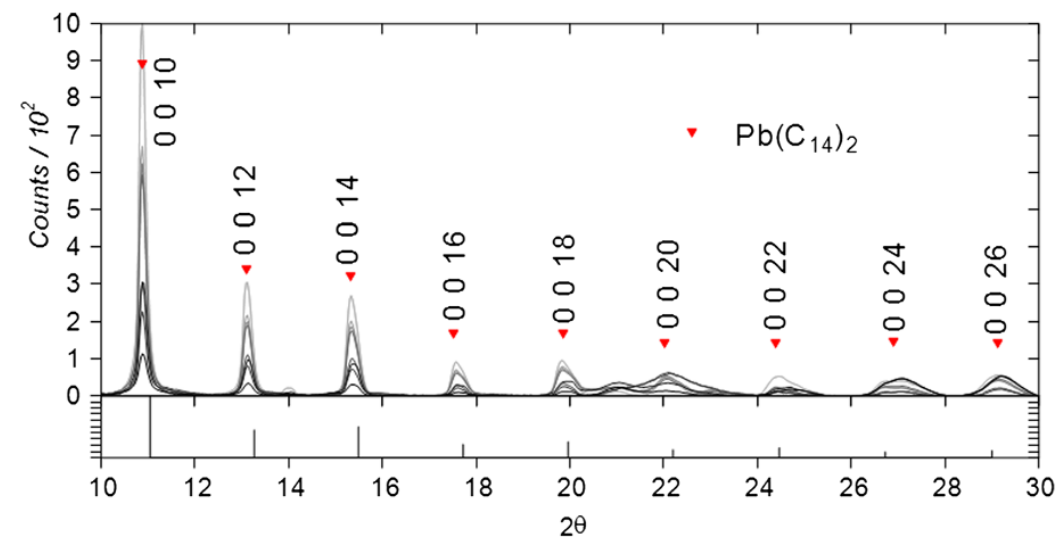

Figure 2 Time-lapse XRD of the coating process. Bare lead was soaked for 10 hours in $0.05 \mathrm{~mol}^{-1}$ tetradecanoic acid $\left(\mathrm{C}_{14}\right)$ (upper panel) followed by a 1 hour drying stage in ambient air (lower panel) (A). $\mathrm{Pb}\left(\mathrm{C}_{14}\right)_{2}$ growth on a bare lead substrate during drying is shown in (B). First scan (black) to last scan (grey).

\section{Coating mass thickness}

The XRD pattern of the lead tetradecanoate coating deposited from $0.05 \mathrm{~mol} \mathrm{~L}^{-1}$ tetradecanoic acid solution has been studied previously [13]. Patterns from lead samples coated with a range of concentrations of tetradecanoic acid are shown in Figure 4A. Although only one sample was used per concentration, the data (peak locations) are in agreement with previous results [13]. At all concentrations from $0.01 \mathrm{~mol} \mathrm{~L}^{-1}-1 \mathrm{~mol} \mathrm{~L}^{-1}$, the coating forms although at higher inhibitor concentrations unreacted tetradecanoic acid is also detected. On samples with unreacted tetradecanoic acid, the unreacted acid forms a white crust which can be removed easily with ethanol. The XRD pattern with the least contamination is given by the lead coated with a $0.01 \mathrm{~mol} \mathrm{~L}^{-1}$ solution in which only lead and lead tetradecanoate peaks feature. It is uncertain whether excess tetradecanoic acid on the surface would afford improved protection from atmospheric pollutants, but the unaesthetic appearance resulting from excess acid means higher inhibitor concentrations are not recommended.

The lead metal reflections are smaller for samples coated with lower inhibitor concentrations indicating that the coating of lead tetradecanoate is thicker for low concentrations. A thicker superficial lead compound will absorb more of the X-rays arriving at and reflected from the underlying lead surface leading to a reduction in lead signal.

The extent of absorption by compounds can be measured using the mass attenuation coefficient $[13,14]$ and this leads directly to a method for estimating average layer thickness using the Beer-Lambert law, described in detail previously (equation 3 ref. [13]). Figure 4B shows the results for coating mass thickness calculated using the peak areas for the lead signal. The mass thickness is the mass of the lead ditetradecanoate coating per unit area (and the thickness is this divided by the density). In this way we can quantify the observations from Figure 4A. The mass thickness of the coating from $0.01 \mathrm{~mol} \mathrm{~L}^{-1}$ and $0.05 \mathrm{~mol} \mathrm{~L}^{-1}$ solutions of the acid is the greatest at $0.045 \mathrm{~g} \mathrm{~cm}^{-2}$. The mass thickness of the coating formed from higher concentrations of the acid is up to $30 \%$ lower. Deposition of mixed coatings of acid and lead carboxylate form for the higher concentrations, and the attenuation of the crystalline tetradecanoic acid will be significantly lower than that for the same thickness of lead tetradecanoate. 


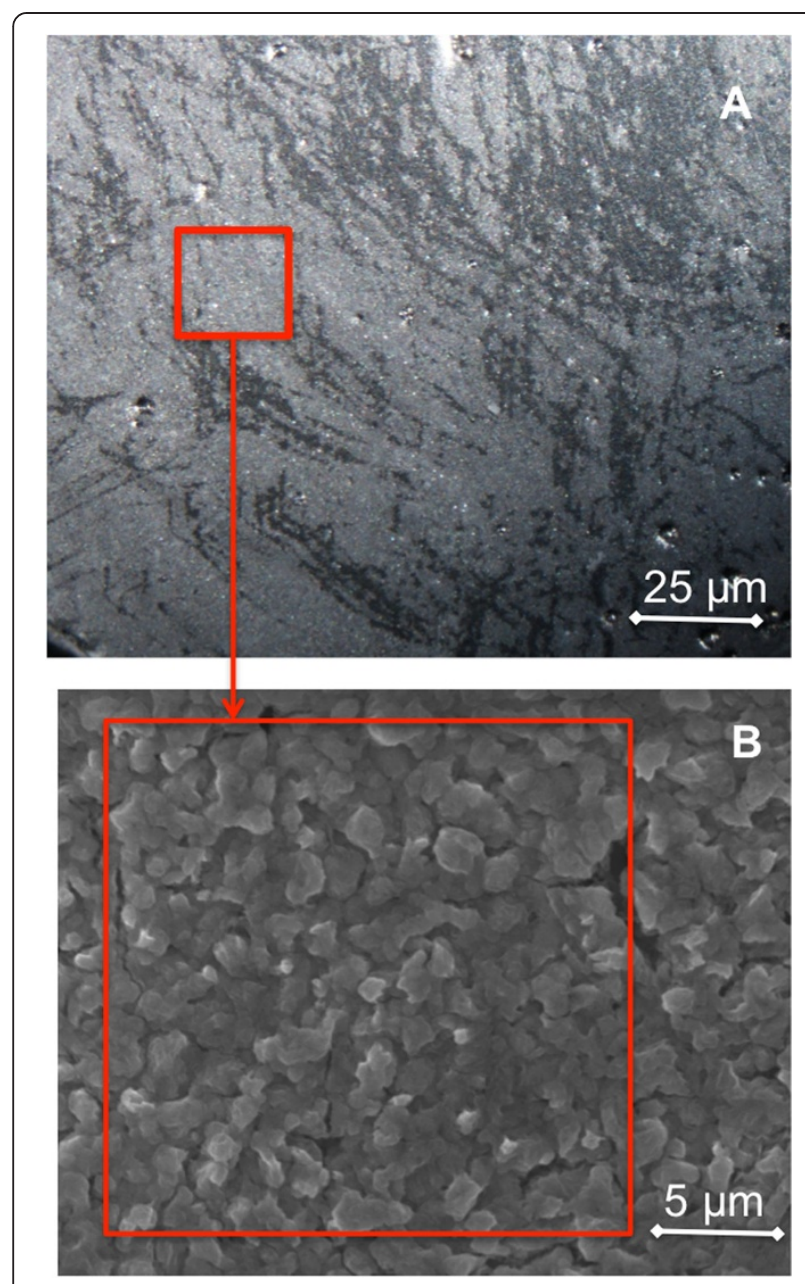

Figure 3 Microscopy of the coated surface. An optical microscopy image (A) and SEM (B) image of a C14 coated lead coupon was recorded after bare lead was coated by immersion for 24 hours.

\section{Effectiveness against acidic pollutants and a longer chain solution}

Electrochemical Impedance Spectroscopy (EIS) can give quantitative data relating to the effectiveness of a coating on a conductive substrate. Here we use EIS to compare the impedance and phase data before and after immersion in acetic acid to see the corrosive effects of the acid modelling VOC emission by oak. In the microscopy data, we see that the coating is easily scratched making it difficult not to damage the coating during mounting into the working electrode holder. Therefore the only reproducible results come from undamaged coatings.

Figure $5 \mathrm{~A}$ shows the Bode impedance plot of the sample measured in an ASTM D electrolyte solution over a specified frequency range before and after immersion in acetic acid. After immersion in acetic acid, the magnitude of impedance of the coating decreases by $15 \%$. The decrease in impedance suggests the aggressive corrosion through the coating by acetic acid. The ASTM D electrolyte initiates corrosion if in contact with lead - ASTM D models atmospheric corrosion thus, lead oxides and carbonates may form. As a consequence of acetic acid immersion the protection from the coating and from the oxide layer decreases and the ASTM D electrolyte can penetrate to the metal surface to initiate corrosion more readily. The corrosion products formed via acetic acid attack do not impart further protection, unlike the passivating lead oxide. This is due to the solubility of the corrosion product (lead acetate) in aqueous solutions such as the electrolyte used here and surface water condensed from the atmosphere on an artefact.

Figure 5B shows the corresponding Bode phase plots these plots clearly show two maxima, or time constants. The maximum at $\sim 10 \mathrm{~Hz}$ corresponds to the double layer, which includes the surface oxide, and that at $\sim 1000 \mathrm{~Hz}$ to the coating. The presence of two time constants indicates the penetration of the electrolyte into the coating and double layer, which increases the surface area of metal exposed to electrolyte. The time constants shown in the phase plots shift to lower frequencies as a result of immersion in acetic acid. This can be linked to the observed decrease in impedance in Figure 5A.

Figure $6 \mathrm{~A}$ compares the impedance of a $\mathrm{Pb}\left(\mathrm{C}_{14}\right)_{2}$ coating against a longer chain lead carboxylate $\mathrm{Pb}\left(\mathrm{C}_{18}\right)_{2}$ coating deposited from the same concentration of ethanolic octadecanoic acid solution across the same range of frequencies. The magnitude of impedance is $20 \%$ higher for the longer chain carboxylate and $75 \%$ higher than bare lead, thus demonstrating its capacity for improved corrosion resistance. In comparison to $\mathrm{C} 14$, the phase plot (Figure 6B) shows the second time constant $(\sim 1000 \mathrm{~Hz})$ shifted to higher frequencies. This could mean that the $\mathrm{Pb}(\mathrm{C} 18)_{2}$ coating is reducing the rate of electrolyte penetration and therefore corrosion. This is presumably due to the longer carbon chains providing a greater area of hydrophobicity to repel aqueous electrolytes from reaching the metal substrate below.

Figure 6B shows an area of negative phase shift at very low frequencies. This can be related to inductive behaviour due to a water-uptake phenomenon of the coating. Negative phase shifts are found at low frequencies of the $\mathrm{PbC} 14$ plots before immersion in acetic acid. Figure $3 \mathrm{~B}$ shows the crystals on the coated surface of this sample - the gaps between crystals could allow for water-uptake into the coating. There is less negative phase shift in the $\mathrm{PbC18}$ coating due to increased hydrophobicity, as previously mentioned.

The lead tetradecanoate is mostly resistive. In addition, Figure 5A shows that the change in impedance of bare lead before and after immersion in acetic acid is the same $(\sim 15 \%)$ as the coated lead. In this way it can be concluded that the lead tetradecanoate coating 

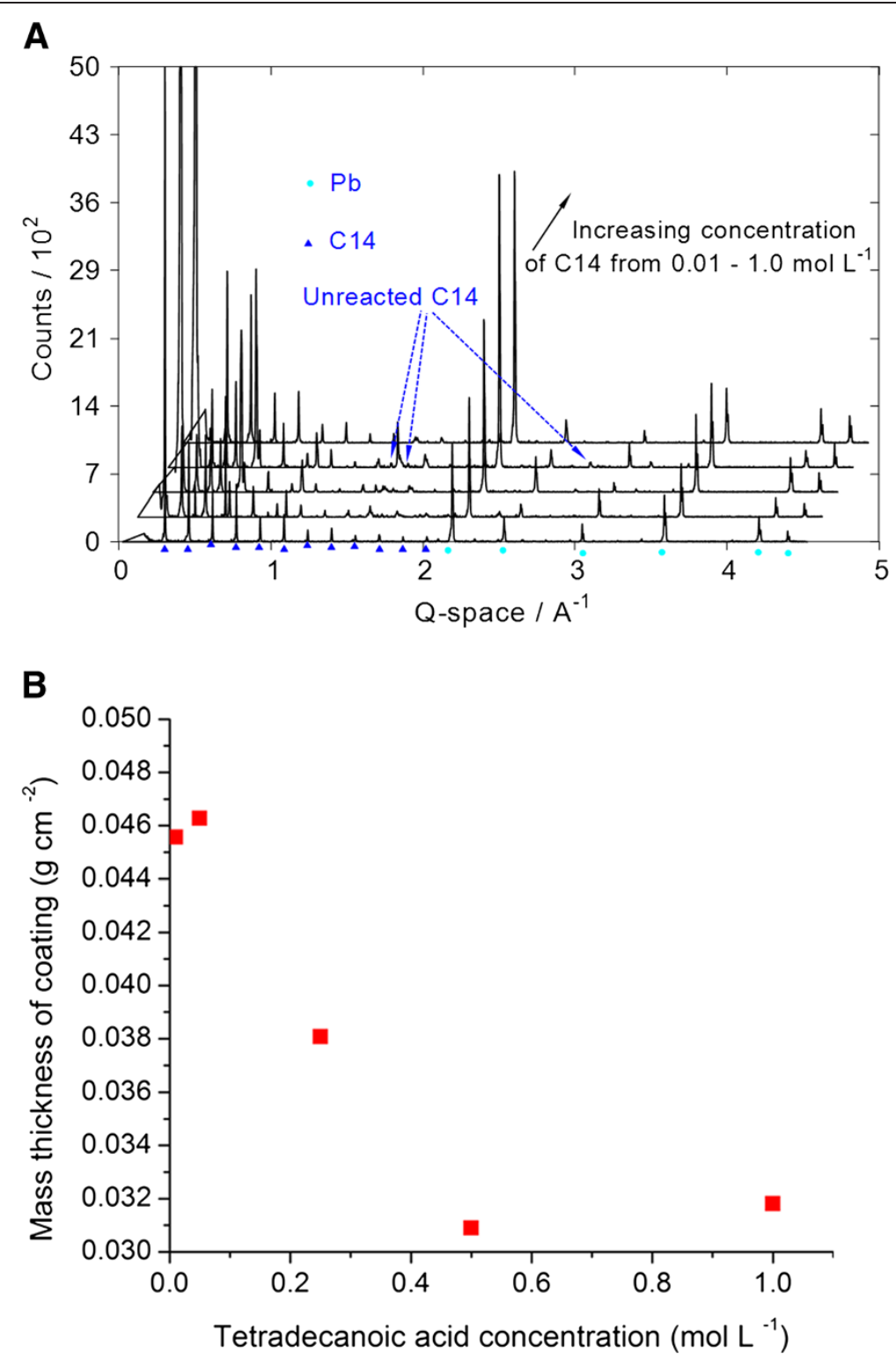

Figure 4 Finding the optimal coating concentration. XRD patterns of a coated lead coupon with increasing inhibitor concentrations were recorded $(\mathbf{A})$. The mass thickness of the coating was calculated using an adapted version of the Beer-Lambert law and the extracted peak area of $\mathrm{Pb} 111[13,14]$. Mass thickness is plotted versus C14 concentration (B).

is passivating the surface, not providing a barrier against pollutants.

\section{Methods}

\section{Sample preparation}

The lead coupon and coating preparation have been described elsewhere [13]. $0.05 \mathrm{~mol} \mathrm{~L}^{-1} \mathrm{C} 18$ and solutions of $1 \mathrm{~mol} \mathrm{~L}^{-1}, 0.5 \mathrm{~mol} \mathrm{~L}^{-1}, 0.25 \mathrm{~mol} \mathrm{~L}^{-1}, 0.1 \mathrm{~mol} \mathrm{~L}^{-1}$, $0.05 \mathrm{~mol} \mathrm{~L}^{-1}$ and $0.01 \mathrm{~mol} \mathrm{~L}^{-1} \mathrm{C} 14$ were similarly prepared. Coupons were immersed in the appropriate solution for 24 hours and left to dry in air.

\section{Analytical methods}

\section{Time-lapse synchrotron $x$-ray diffraction}

Real-time growth was studied for $\mathrm{Pb}\left(C_{14}\right)_{2}$ in two ways. (a) A polished lead coupon $12.5 \mathrm{~mm}$ diameter was immersed in $0.05 \mathrm{~mol} \mathrm{~L}^{-1}$ tetradecanoic acid in ethanol for 10 hours in an environmental cell, the MkIV eCell [15]. During the immersion the surface was analysed in-situ using synchrotron X-ray diffraction on the UK CRG beamline XMaS (BM28) [16] at the European Synchrotron Radiation Facility (ESRF). Surface powder diffractograms were collected for $2 \mathrm{~s}$ every $125 \mathrm{~s}$ using a Mar CCD 165 camera (Mar, USA, Inc.). The sample surface was automatically moved to 

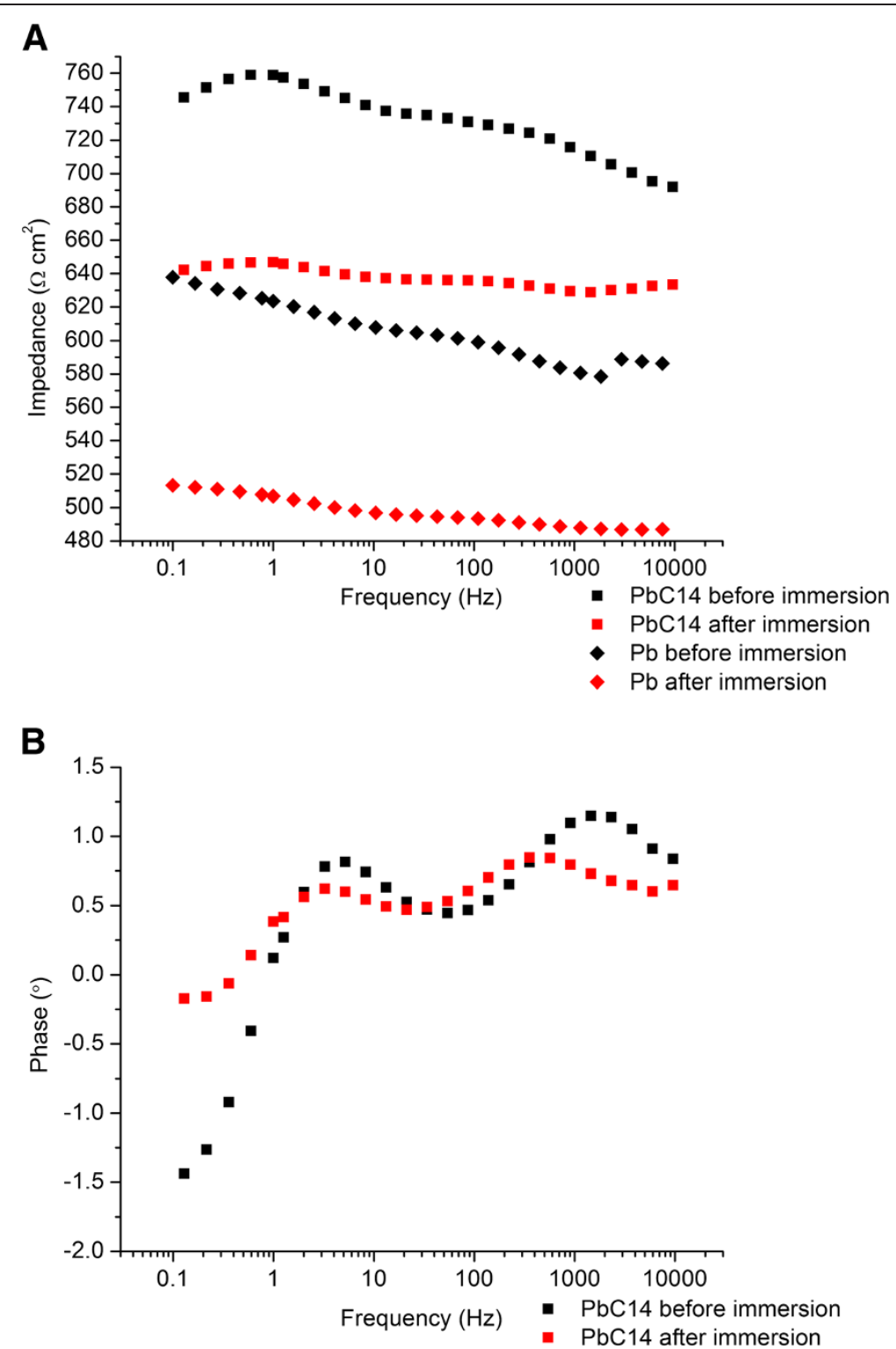

Figure 5 Coating effectiveness in acetic acid. Impedance (A) and phase (B) plots of $\mathrm{Pb}(\mathrm{C} 14)_{2}$ coating and bare lead samples were recorded before and after immersion in acetic acid.

within $125 \mu \mathrm{m}$ of an X-ray transparent, $6 \mu \mathrm{m}$ thick, Kapton ${ }^{\bullet}$ window for $10 \mathrm{~s}$ for $\mathrm{x}$-ray exposure and then moved deeper into the solution to ensure unrestricted growth. It then remained immersed at all times. After 10 hours, the window was removed and the surface allowed to dry until no further changes occurred in the diffraction patterns. (b) In a different experiment conducted on the Belgian-Dutch CRG beamline DUBBLE (BM26a) at the ESRF, the same solution was flowed in $2 \mathrm{~mL}$ droplets across a polished lead sample surface in ambient air. The droplets readily wetted the surface and started evaporating immediately. Using an identical Mar CCD 165 camera a sequence of 10 surface powder diffraction images were recorded with a collection time of 15 seconds and an interval of 30 seconds between scans. During the first four scans $4 \times 2 \mathrm{~mL}$ aquilots of the solution was flowed over the surface using PTFE piping fixed to the top of the sample. The remaining six scans observed the drying and coating formation, although some evaporation occurred between the first four scans. SR-XRD patterns from (i) and (ii) above were extracted and analysed using the esaProject software [17] which can produce images such as those shown in Figure 2.

\section{Laboratory XRD}

XRD measurements were performed using a ARL X'TRA diffractometer using $\mathrm{Cu}-\mathrm{K}_{\alpha} \mathrm{X}$-rays with a wavelength of $1.5405 \AA$ with a scintillation counter detector. A scan from $2-67^{\circ} 2 \Theta$ was performed on each sample 


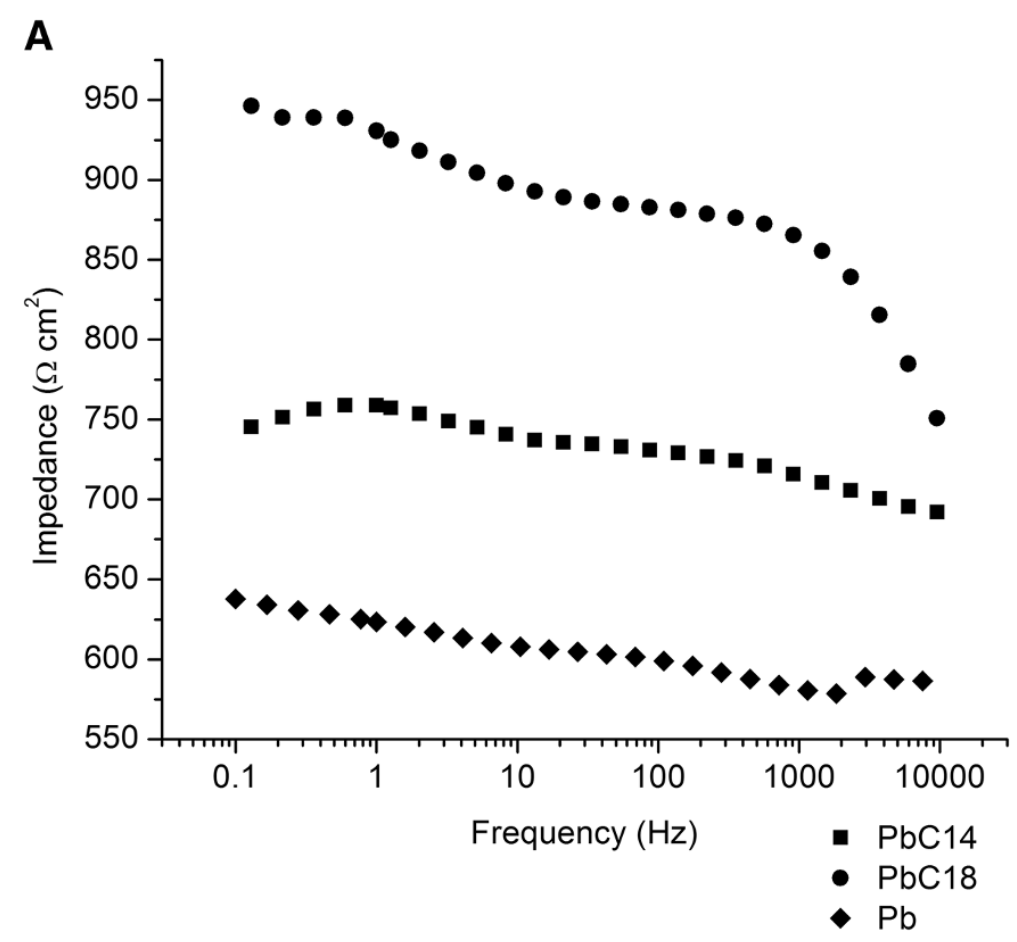

B

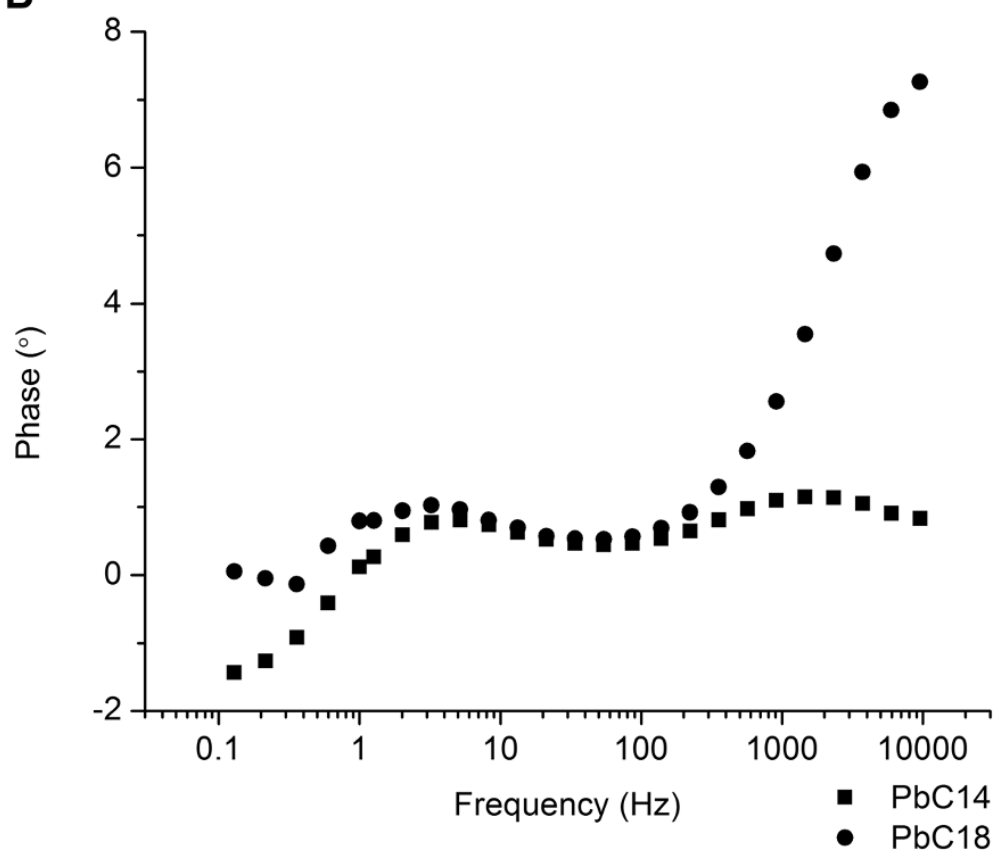

Figure 6 The effect of increasing coating carbon chain length. Impedance (A) and Bode phase plots (B) were recorded of bare lead and $\mathrm{Pb}$ $(\mathrm{C} 14)_{2}$ and $\mathrm{Pb}(\mathrm{C} 18)_{2}$ coating on lead.

at a scan rate of $0.8^{\circ}$ minute and a step size of $0.02^{\circ}$. One sample per concentration was measured.

\section{Microscopy}

SEM images of $0.05 \mathrm{~mol} \mathrm{~L}{ }^{-1} \mathrm{C} 14$ coated coupons were collected on a ZEISS SUPRA 55-VP microscope at
$20 \mathrm{kV}$ acceleration voltage. Optical microscope images were collected on a Nikon SM2800 microscope.

\section{Electrochemical impedance spectroscopy}

Impedance measurements were performed using a PGS TAT20 potentiostat with a FRA2 frequency response 
analysis module. Data were acquired over a frequency range of $100 \mathrm{mHz}$ to $10 \mathrm{kHz}$ (0.1 V signal amplitude). The frequency range $10 \mathrm{kHz}-1 \mathrm{~Hz}$ was distributed logarithmically across the first 40 points and from $1 \mathrm{~Hz}-100$ $\mathrm{mHz}$ logarithmically over the last 10 points. Measurements were controlled by the Nova software (version 1.8). For all experiments a three-electrode system in a glass cell was used. The set-up consisted of a saturated calomel electrode (SCE), a carbon counter electrode and the lead coupon mounted in a working electrode holder. The electrolyte used was ASTM D 1384-87, which models a typical atmospheric environment for lead and is a standard electrolyte for corrosion inhibition tests [18]. For the immersion tests, bare and coated coupons were tested for impedance before and after immersion in $0.01 \mathrm{~mol} \mathrm{~L}^{-1}$ acetic acid solution for 10 minutes. Samples were rinsed with deionised water before and after immersion. All EIS measurements were repeated three times.

\section{Conclusions}

Long chain carboxylates are easy to prepare and quick to apply to lead surfaces when an ethanolic solution of the carboxylic acid is used. Evaporation of the solvent leaves behind the $\mathrm{Pb}\left(\mathrm{C}_{14}\right)_{2}$ coating only, if the correct inhibitor concentration is used. For this lead surface preparation method, a concentration of between 0.01 and $0.05 \mathrm{~mol} \mathrm{~L}^{-1}$ is optimal. This will afford a coating mass thickness of approximately $0.045 \mathrm{~g} \mathrm{~cm}^{-2}$.

Impedance tests of the coating showed that the coating is susceptible to electrolyte penetration, especially by acetic acid. Coatings prepared using longer chain carboxylates, are less susceptible to electrolyte penetration, although the compounds become progressively less soluble in ethanol.

Further work will concentrate on longer chain carboxylates as coatings for lead, the coating of corroded lead samples (without prior surface preparation) and the long-term stability of these coatings in less aggressive environments. In addition the coating method will be reviewed. At present the mounting of the sample within the working electrode holder can cause damage to the coating (as seen in the microscopy results). The result of this damage is irreproducibility in the impedance data. Coating bare samples after mounting in the working electrode holder is possible, and demonstrates the ease of application of this coating.

\section{Competing interests}

The authors declare that they have no competing interests.

\section{Authors' contributions}

RG wrote the manuscript revised by MGD and MDK. RG made the samples and performed analytical measurements (with the exception of the XRD analyses). RG, AA and MGD devised the synchrotron experiments and the eCell system, and MGD wrote the data reduction software esaProject. All authors read and approved the final manuscript.

\section{Acknowledgements}

We would like to thank the Physics Department at Warwick University for studentship of R. Grayburn, Tom Plankaert (UGent) for the XRD analyses, and to Lapon Orgelbouw, Diksmuide for the introduction to organ manufacture.

\section{Author details}

${ }^{1}$ Department of Physics, University of Warwick, Coventry CV4 7AL, UK. ${ }^{2}$ Department of Analytical Chemistry, Ghent University, Ghent 9000, Belgium. ${ }^{3}$ DUBBLE (BM26), European Synchrotron Radiation Facility, BP 220, 38043 Grenoble, France. ${ }^{4} \mathrm{XMaS}$ (BM28), European Synchrotron Radiation Facility, BP 220, 38043 Grenoble, France. ${ }^{5}$ Department of Physics, University of Liverpool, Liverpool L69 7ZE, UK.

Received: 24 February 2014 Accepted: 6 June 2014

Published: 17 June 2014

\section{References}

1. Schotte B, Adriaens A: Treatments of corroded lead artefacts: an overview. Stud Conservat 2006, 51:297-304.

2. Åslund A, Speedstra J: The COLLAPSE Project: Corrosion of Organ Pipes Causes and Recommendations. Luxembourg: Publications Office of the European Union; 2011.

3. Rocca E, Steinmetz J: Inhibition of lead corrosion with saturated linear aliphatic chain monocarboxylates of sodium. Corros Sci 2001, 43:891-902.

4. Dowsett M, Adriaens A, Schotte B, Jones G, Bouchenoire L: In-situ spectroelectrochemical study of the growth process of a lead decanoate coating as corrosion inhibitor for lead surfaces. Surf Interface Anal 2009, 41:565-572.

5. Dowsett M, Adriaens A, Schotte B, Jones G: Real time spectroelectrochemical growth and corrosion resistance monitoring of lead carboxylate coatings in an environmental cell ( eCell ). In Proceedings of the Interim Meeting of the ICOM-CC Metal Working Group, Amsterdam, 17-21 September 2007. Volume 3. Edited by Degrigny C, van Langth R, Joosten I, Ankersmit B. Amsterdam: Rijksmuseum; 2007:26-31.

6. De Wael K, Keersmaecker M, Dowsett M, Walker D, Thomas PA, Adriaens A: Electrochemical deposition of dodecanoate on lead in view of an environmentally safe corrosion inhibition. J Solid State Electrochem 2009, 14:407-413.

7. De Keersmaecker M, De Wael K, Adriaens A: The use of lead dodecanoate as an environmentally friendly coating to inhibit the corrosion of lead objects: Comparison of three different deposition methods. Prog Org Coat 2012, 74:1-7.

8. Adriaens A, De Bisschop F, Dowsett M, Schotte B: Growth and real time corrosion resistance monitoring of lead decanoate coatings. App/ Surf Sci 2008, 254:7351-7355.

9. Elia A, Dowsett M, Adriaens A: On the use of alcoholic carboxylic acid solutions for the deposition of protective coatings on copper. In International Conference of Metal Conservation: Interim Meeting of the International Council of Museums Committee for Conservation Metal Working Group (ICOM - 2010). Edited by Mardikian P, Chemello C, Hull P, Watters C. South Carolina, USA: Clemson University; 2010:144-150.

10. Elia A, Wael K, Dowsett M, Adriaens A: Electrochemical deposition of a copper carboxylate layer on copper as potential corrosion inhibitor. J Solid State Electrochem 2011, 16:1-6.

11. Mirambet F, Reguer S, Rocca E, Hollner S, Testemale D: A complementary set of electrochemical and X-ray synchrotron techniques to determine the passivation mechanism of iron treated in a new corrosion inhibitor solution specifically developed for the preservation of metallic artefacts. Appl Phys A 2010, 99:341-349.

12. Mauchauffee $S$, Meux E, Schneider M: Determination of the solubility products in water at $20^{\circ} \mathrm{C}$ of 32 metallic carboxylates. Ind Eng Chem Res 2008, 47:7533-7537.

13. Grayburn R, Dowsett M, De Keersmaecker M, Westenbrink E, Covington JA, Crawford JB, Hand M, Walker D, Thomas PA, Banerjee D, Adriaens A: Timelapse synchrotron $\mathrm{X}$-ray diffraction to monitor conservation coatings for heritage lead in atmospheres polluted with oak-emitted volatile organic compounds. Corros Sci 2014, 82:280-289.

14. X-Ray Form Factor, Attenuation and Scattering Tables: [http://www.nist.gov/ $\mathrm{pml} / \mathrm{data} / \mathrm{ffast} / \mathrm{index.ffm]}$. 
15. Dowsett MG, Adriaens A: Cell for simultaneous synchrotron radiation $X$-ray and electrochemical corrosion measurements on cultural heritage metals and other materials. Anal Chem 2006, 78:3360-3365.

16. Brown SD, Bouchenoire L, Bowyer D, Kervin J, Laundy D, Longfield MJ, Mannix D, Paul DF, Stunault A, Thompson P, Cooper MJ, Lucas CA, Stirling WG: The XMaS beamline at ESRF: instrumental developments and highresolution diffraction studies. J Synchrotron Radiat 2001, 8:1172-1181.

17. Adriaens A, Dowsett M, Leyssens K, Van Gasse B: Insights into electrolytic stabilization with weak polarization as treatment for archaeological copper objects. Anal Bioanal Chem 2007, 387:861-868.

18. D15.06 Subcommittee: ASTM D1384-87 Standard Test Method for Corrosion Test for Engine Coolants in Glassware. In Engine Coolants; Halogenated Organic Solvents and Fire Extinguishing Agents; Industrial and Specialty Chemicals. West Conshohocken: ASTM; 1988.

doi:10.1186/2050-7445-2-14

Cite this article as: Grayburn et al:: Towards a new method for coating heritage lead. Heritage Science 2014 2:14.

\section{Publish with ChemistryCentral and every scientist can read your work free of charge \\ "Open access provides opportunities to our colleagues in other parts of the globe, by allowing anyone to view the content free of charge." \\ W. Jeffery Hurst, The Hershey Company. \\ - available free of charge to the entire scientific community \\ - peer reviewed and published immediately upon acceptance \\ - cited in PubMed and archived on PubMed Central \\ - yours - you keep the copyright \\ Submit your manuscript here: \\ http://www.chemistrycentral.com/manuscript/<smiles>c1ccccc1</smiles> 